\title{
Use of battery swapping for improving environmental balance and price- performance ratio of electric vehicles
}

\author{
Steffen Schmidt \\ Dipl. Ing. for electrical engineering (ret.), Erfurt, Germany; \\ sus-schmidt@kabelmail.de
}

07 January 2021

\begin{abstract}
There is a simple concept that can significantly improve the environmental balance of battery electric vehicles and at the same time avoid the known disadvantages of these vehicles (short range, long charging times, high acquisition costs) without having to wait for further developed batteries or a higher proportion of green electricity. For this purpose, the vehicles are equipped with built-in batteries for short and medium distances and are therefore sufficient for the majority of daily journeys. For long-distance journeys, the driver borrows charged additional battery packs at swapping stations, which are automatically inserted into a standardised exchange slot within a few minutes.

This paper focuses on the improvements in electric vehicles that can be achieved by combining built-in and exchangeable battery technique and also on the practical feasibility of the concept. It is shown that the battery capacity required for the entire vehicle fleet can be significantly reduced. The resulting ecological advantages on the one hand and grid-stabilising effects of a nationwide network of swapping stations on the other hand, support the transition to environmentally sustainable mobility.

The characteristics of the concept presented are advantageous for its practical implementation. The acceptance by customers and manufacturers can thus be improved compared to previous battery swapping systems. The loan system for the exchange batteries may be designed conveniently-and information security as well as data protection will be strictly complied.
\end{abstract}

Keywords: battery-electric vehicles; range extension; manufacturer-specific built-in battery; exchangeable additional battery; swapping station; environmental balance 


\section{Introduction}

In order to achieve the climate protection targets in the mobility sector - in particular a significant reduction in $\mathrm{CO}_{2}$ emissions - there is obviously no alternative to the mass introduction of battery electric cars (BEVs). To accomplish the climate targets for 2030 in Germany, for example, around 10 to 12 million electric vehicles must be on the roads by that time. These would have to account for more than half of new registrations [01]. However, the BEVs are not yet accepted sufficiently by the costumers [02], because of high prices, short ranges and long charging times. To improve acceptance, e.g. in Germany promotional measures such as purchase bonuses and the expansion of the charging infrastructure are planned [03], but this is not well suited to avoid the disadvantages.

In addition to increasing BEV's numerical share of the total vehicle fleet, it is crucial to achieve the best possible environmental balance for these vehicles. According to [01], the environmental balance of electric vehicles includes "in addition to the climate impact, effects on air quality, on the availability of raw materials and on social conditions, for example in the mining of raw materials ... . ... In this context, the climate balance means the greenhouse gas emissions during the entire life cycle (manufacture, operation, production of electricity ...) of a battery electric car.”

The climate balance of the BEVs is currently only slightly better compared to conventional vehicles with combustion engines [01]. The main reasons for this are the relatively high greenhouse gas emissions from the production of traction batteries for the BEVs and the greenhouse gas emissions due to electricity generation. In addition, there is the environmental impact of the extraction of raw materials for the batteries. There is well-founded hope that the environmental balance can be continuously improved in the future by further improving the batteries and the associated production technology and by increasing the percentage of green energy in the electricity mix. However, further technical developments in batteries will not allow a decisive breakthrough in the foreseeable future [04]. Therefore it would be important to use the further advanced batteries to improve the environmental balance of the BEVs. But current developments are leading to ever larger battery capacities per vehicle, which tend to worsen the vehicle weight as well as environmental balance and are not even needed for the majority of the daily trips.

Plug-in hybrid vehicles (PHEVs) offer an acceptable range despite smaller batteries, but also have a high purchase price due to the more complex technology compared to BEVs. Their environmental balance is definitely not better [05] and is also strongly dependent on the driving behaviour of the user. Future improvements in battery technology and the electricity mix cannot have the same positive effect compared to BEVs [05].

Increasingly higher charging capacities of the fast charging stations are also problematic. There are higher loads for the power grid and grid disturbances due to harmonics [06]. To counteract this, additional energy buffers must be used. Even if disused BEV batteries are used for this purpose, valuable resources are locked up. Fast charging also has disadvantages for battery longevity [07]. Furthermore, there are problems if many users want to access the system simultaneously during peak periods, e.g. at the start of holidays [08].

Starting from the weak points of existing battery and charging systems for electric vehicles, this paper aims to present an improved concept for this, to assess its properties and to investigate its feasibility.

At present, BEVs are usually charged by connecting them directly to a charging station "Plug In". Depending on the usable charging power, the charging process takes some time while the BEV is not mobile. Alternatively, it is possible not to charge the batteries in the vehicle, but to exchange the empty battery in a swapping station for a fully charged battery. This process is much faster than charging at a charging station. Prerequisites for this are specially equipped BEVs and swapping stations that can (automatically) change, charge, store and maintain batteries [09]. 


\section{Application of battery swapping technology to expand the range of BEVs in line with demand}

\subsection{Battery swapping technology up to now}

The obvious solution to eliminate some of the the disadvantages of the BEVs mentioned above is to use exchangeable batteries. In fact, several such projects have already been implemented in practice.

Until 2013 the company Better Place [10] operated electric vehicles with exchangeable batteries and the associated swapping stations. Unfortunately it went bankrupt. The positive aspect about the project is that something like a field test for battery swapping technology has already been carried out and the relevant knowledge is available. The fact that the project failed was not due to the technology, but mainly due to the business model, the lack of support from car manufacturers and that perhaps it was a little too far ahead of its time.

The company Tesla also dealt with battery swapping technology in the past, but had to give it up due to a lack of customer acceptance. In [11], the structure and function of a Tesla battery swapping station is described, which can be regarded as a typical example of this technology.

Currently the Chinese company NIO produces such BEVs and operates the associated swapping stations [12], but only for vehicles of its own brand.

The projects mentioned above have shown that for successful implementation, disadvantages still need to be eliminated and doubts overcome:

- Customer acceptance is low, as there is a dependence on the operators of the battery swapping stations (in terms of price and availability). With certain battery change models, there is also the fear of exchanging one's own good battery for a worse one when changing.

- Support from car manufacturers is also low, as they consider battery technology as their core competence and fear losing market share to the operators of the swapping stations. Furthermore, a (standardised) exchangeable battery pack would limit their freedom of design.

- The necessary standardisation of exchangeable battery packs could hamper technical progress in the further development of battery technology.

- It is feared that the cost of the necessary infrastructure and logistics would be disproportionately high.

- There are legitimate concerns about compliance with data protection. Movement profiles of users could be created through battery lending.

\subsection{Combined battery technology}

The current challenges with the introduction of BEVs can be solved with a well-integrated combination of built-in batteries and manufacturer independent standardised exchangeable additional battery packs and associated battery swapping stations (e. g. located at petrol stations).

The idea of combining built-in batteries with exchangeable batteries has been featured for some time in contributions to online forums on electric mobility $[13,14]$. Such concepts are also proposed in the academic literature. In [15], for example, a combination of fixed batteries with manually exchangeable additional batteries is shown. A detailed consideration of such a concept with fast automatic change of the additional battery is given in [16] and [17]. There, the impact of this concept on energy consumption and the total cost of ownership of the vehicle is also examined. 
In [18], such a concept is considered in conjunction with a network of battery swapping stations, taking into account both technical and socio-economic impacts.

For the following considerations, it should be assumed that such a car is equipped with a built-in battery which could be used for a range of about $100 \ldots 200 \mathrm{~km}$ and thus is sufficient for the predominant part of daily trips. This battery can be charged at normal charging station for BEVs (e.g. at home or at work). In the event that the vehicle is to be used for a longer journey, it has a slot for exchangeable, standardised battery packs for a range of, for example, $200 \ldots 400 \mathrm{~km}$. Larger vehicles could have more of those slots. These are normally empty, but can be equipped within a few minutes at a petrol station with a battery swapping station if required. Empty battery packs can also be quickly exchanged there for charged ones. A corresponding driving regime is shown in Figure 1.

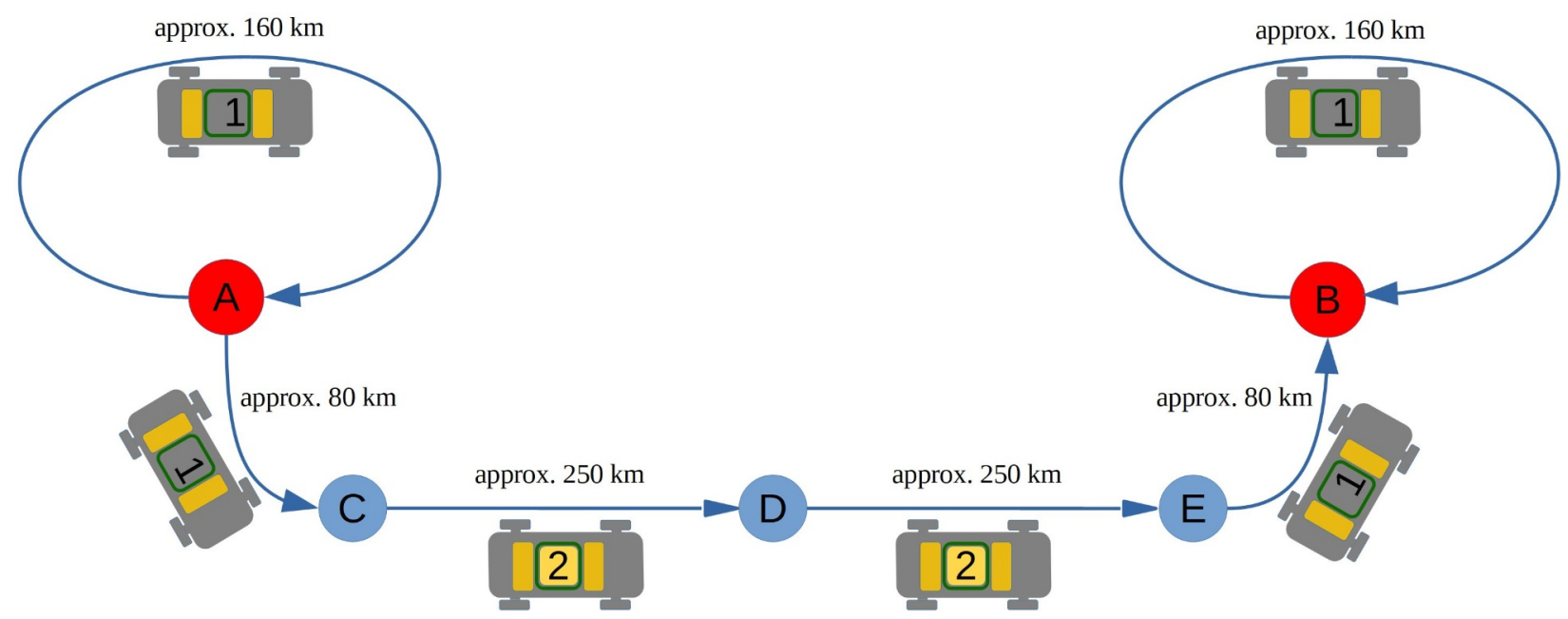

Figure 1: Typical driving regime of a BEV with additional battery,

A: Place of residence with BEV charging station, B: Long range travel destination with BEV charging station, C: Swapping station - pick up additional battery, D: Swapping station - change additional battery, E: Swapping station - drop off additional battery, 1: BEV runs without additional battery, 2: BEV runs with additional battery

This concept can be implemented with the technology available today and would have the following advantages over today's electric vehicles:

- The battery capacity required for the entire vehicle fleet is considerably lower because of shared battery packs than if each vehicle had to be constantly equipped with the maximum capacity (see section 3.3). This can significantly improve the environmental balance of the vehicles (see section 3.4).

- The battery packs available at the exchange stations can easily be used as buffers for the energy supply grid and thus support the transition to renewable energies. This function also enables proportional financing of the swapping technology (see section 5.4). Thus the deterioration of the batteries caused by the "bidirectional charging" is not at the customer's expense.

- The purchase costs of the vehicle are lower because of smaller batteries. There are also cost advantages over the entire vehicle service life $[16,17]$.

- The range of the vehicle is completely sufficient for most daily trips and can be quickly extended as required. 
- Charging time is not a problem. The batteries at the swapping stations can be charged more slowly and longevity conserved without reducing the availability of the vehicle.

- In normal operation (without additional battery pack) the weight of the vehicle is significantly lower. This leads to reduced energy consumption $[16,17]$ and has advantages for driving behaviour.

- The smaller battery capacity also has safety advantages. In the event of a vehicle accident, less stored energy can be released and less flammable material is carried in the battery, reducing the risk of fire [19].

- The exchangeable battery packs are used more intensively and can be kept up to date with the latest technology (e.g. in terms of capacity). Older vehicles also benefit from this.

- A battery pack received at a swapping station has the optimal operating temperature, which is particularly advantageous in winter.

- If there is still a high demand for fast charging stations for BEVs with permanently built-in batteries in the future, it would even be possible to combine these with the swapping stations. This would have the advantage that the battery packs stored there could also serve as a buffer for the fast-charging stations, thus reducing the load on the grid.

Compared to the BEVs with a permanently built-in battery or the exchange technology used so far, there are also disadvantages:

- Each long-distance journey requires at least 2 stops at changing stations (picking up the additional battery at the beginning and dropping off the exchangeable battery pack at the end of the journey). However, the time required for this is relatively short. On very long journeys, the battery of a "conventional" BEV also has to be recharged, and in this case the battery replacement technology has time advantages. Future autonomous vehicles could also pick up and drop off the exchangeable battery independently of the actual journey at a swapping station close to the vehicle's location.

- To ensure the availability of the battery packs at the swapping stations, logistical measures in the form of transports of the additional batteries are necessary (see section 4.3).

- The different vehicle weight for journeys without and with additional battery requires appropriate consideration in the design of the running gear and control electronics of these vehicles.

- Some of the above-mentioned advantages are relativised by the further development towards cheaper, lighter and more resource-efficient batteries.

\subsection{Construction of a BEV with exchangeable additional battery}

The design (see figure 2) corresponds to that of the current BEV, with the difference that an exchange slot for a standardised additional battery with the respective interfaces for power electrics, control technology and cooling technology is provided at an exposed position on the vehicle (in the underbody). 


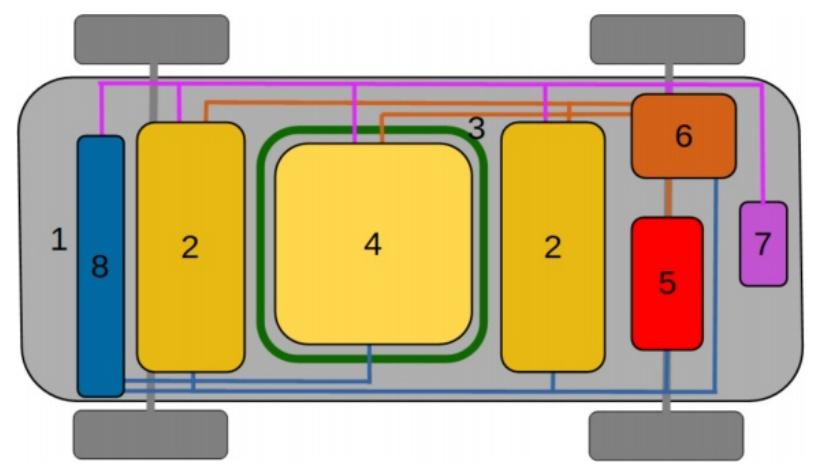

1: car platform

2: built-in batteries

3: exchange slot

4: exchangeable additional battery pack

5: electric motor

6: power electronics

7: control electronics

8: cooling system

Figure 2: Main components of a BEV with exchangeable additional battery pack

The battery pack (see figure 3) is standardised across manufacturers and has the above-mentioned interfaces. It is also equipped with a smart device that monitors the status of the module (battery wear, state of charge, etc.) [18]. The latter also performs the functions required for the lending regime (see sections 5.2 and 5.3). In order to realise the function of the special reserve modules for traffic peaks described in section 4.4 an integrated charger can be provided as an option.

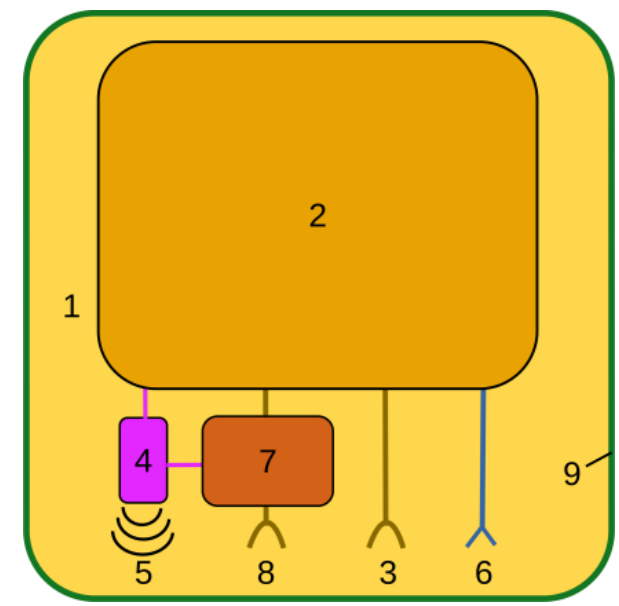

1: exchangeable battery pack

2: battery cells

3: connector for drive power

4: smart device

5: wireless connection

6: connector for coolant

7: charger*

8: connector for charging energy*

9: enclosure

*) optional for modules not participating in the exchange regime

Figure 3: Main components of an exchangeable battery pack

To connect the exchangeable battery pack with the DC-bus of the built-in vehicle batteries an additional DC/DC-converter is necessary (see figure 4). This can also ensure that the built-in battery is recharged while driving with a battery pack so that there is still ample range when the battery pack is returned. A unidirectional DC/DC converter is sufficient for this purpose. This can easily be implemented if the nominal voltage of the additional battery pack is designed to be higher than that of the built-in batteries. The built-in batteries are additionally charged by recuperation.

If dynamic driving behavior is to be achieved even with the smaller built-in battery alone, the vehicle can be equipped with an energy buffer based on an ultracapacitor [18, 20]. This also reduces the load on the battery and increases the effectiveness of recuperation. 


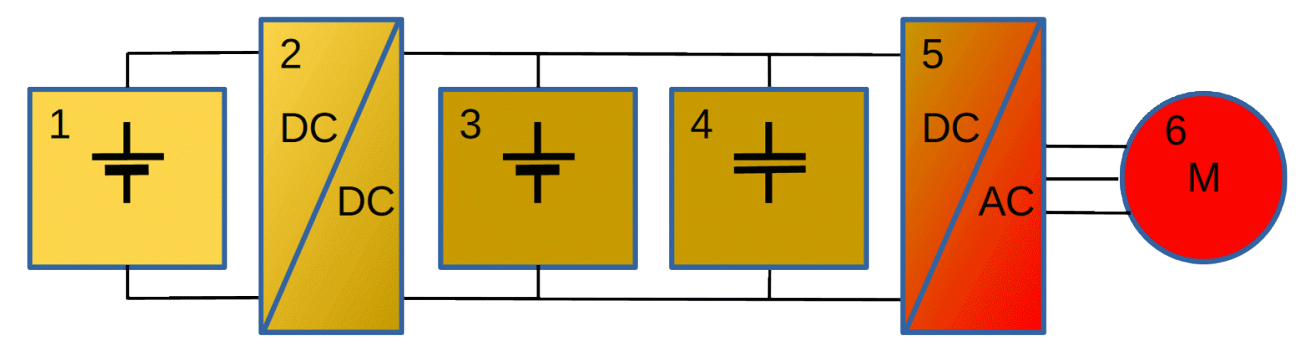

1: additional battery

2: DC/DC-converter

3: built-in battery

4: energy buffer with

ultracapacitor (optional)

5: frequency converter

6: drive motor

Figure 4: Simplified diagram of a BEV with additional battery

\subsection{Comparison with previously implemented battery swapping technology}

The combination of manufacturer-specific built-in batteries and standardised exchangeable battery packs differs significantly from the projects described in section 2.1 and offers additional advantages that can be used for ecological improvements in mobility. In addition, there are characteristics that can improve acceptance by customers and manufacturers and would thus favour practical implementation:

- The manufacturers have more freedom of design due to the built-in batteries and can enhance the current technology of batteries and charging devices.

- They would not lose the market for traction batteries and would still be able to sell the majority of the batteries required for the vehicle fleet together with their vehicles.

- Thanks to the built-in battery, the vehicle can also be used independently of the swapping stations. The customer owns a "full-fledged" vehicle with its own battery. From experience with previous swapping systems, this is an important touchstone for the acceptance of this technology [18].

- The exchangeable batteries are only used as "range extender" if necessary. This means that the installation of the swapping stations should not be as urgent and can be done as required (e.g. initially only along the motorways). Since the petrol stations will sell less fuel in the future, it would be possible to operate exchange stations there.

\section{Considerations about number and size of the additional batteries}

\subsection{Preconditions and objectives}

- Additional battery packs are standardised across manufacturers. Ideally there is only one type for all BEVs (see table 1).

- Additional battery packs only serve to extend the driving range for long distance trips and are not necessary for normal daily trips.

- For the following estimates, it is assumed that the usage data (annual mileage and route lengths [21]) of the BEVs with the exchange technology presented correspond to that of the entire vehicle fleet in Germany. This may not be the case until they represent a large part of the fleet. 
Table 1: Possible options for equipping cars with exchange slots for battery packs

\begin{tabular}{|l|l|l|l|}
\hline $\begin{array}{l}\text { Vehicle classes } \\
\text { according to } \\
\text { [22]. }\end{array}$ & $\begin{array}{l}\text { mini cars, } \\
\text { small cars }\end{array}$ & $\begin{array}{l}\text { medium cars, } \\
\text { large cars }\end{array}$ & $\begin{array}{l}\text { executive cars, luxury cars, } \\
\text { SUV, multi purpose cars, } \\
\text { Pick-up, } \\
\text { light comercial vehicles }\end{array}$ \\
\hline Equipment & no exchange slot & 1 exchange slot & 1 or 2 exchange slots \\
\hline Note & $\begin{array}{l}\text { not necessary, since } \\
\text { mainly designed for } \\
\text { urban traffic and short } \\
\text { distances }\end{array}$ & $\begin{array}{l}\text { reference class for } \\
\text { design of the } \\
\text { exchangeable battery } \\
\text { pack }\end{array}$ & $\begin{array}{l}\text { depending on size and energy } \\
\text { requirements }\end{array}$ \\
\hline
\end{tabular}

\subsection{Rough estimation of the required quantity of exchangeable battery packs}

The basic range of $100 \ldots 200 \mathrm{~km}$ proposed in section 2.2 is sufficient for $95 \%$ of daily journeys, according to [21]. On condition that the BEVs are equipped with built-in batteries sufficient for this range, it is necessary to hold available battery packs for an average $5 \%$ of them. In addition, a sufficient reserve is needed for cars that need more than one battery pack per day, for possible irregularities in demand and for price-sensitive charging management (see section 5.4). To cover this additional demand, it is assumed here that 2 additional battery packs per car are needed.

Additional battery packs are only needed for a few hours a day (to cover a distance and to recharge the built-in battery). Therefore it can be assumed that most of the battery packs may be loaned out twice a day and thereby this expansion demand can be covered. Thus a number of battery packs equal to $5 \%$ of the BEVs would be sufficient.

\subsection{Rough estimation of the potential for saving battery capacity}

Current BEVs for mass consumption are, for example, equipped as follows in the higher-end version [23]:

- Tesla Model 3 Long Range:

- VW ID.3 Pro S:

- Hyundai Kona electric:

- Opel Ampera-e:
$580 \mathrm{~km}$ range,

$549 \mathrm{~km}$ range,

$484 \mathrm{~km}$ range,

$520 \mathrm{~km}$ range,
75 kWh battery capacity

77 kWh battery capacity

64 kWh battery capacity

60 kWh battery capacity.

Due to technical developments, it can be assumed that in the near future a conventional BEV will be equipped with a built-in battery as standard for a range of approx. $500 \mathrm{~km}$ (equivalent to approx. 75 kWh for medium cars).

In comparison, a BEV with a basic range of $200 \mathrm{~km}(30 \mathrm{kWh})$ and if necessary an additional battery pack for a range of $300 \mathrm{~km}(45 \mathrm{kWh})$ requires only

$(30 \mathrm{kWh}+(45 \mathrm{kWh} * 5 \%)) / 75 \mathrm{kWh}=43 \%$

of this battery capacity (across the entire vehicle fleet).

To assess the potential for saving batteries in real terms, the comparison must also take into account the service life of the batteries under the different operating conditions. Battery ageing depends on the number of charging cycles, charging behaviour, driving style and temperature, for example [24]. To simplify this estimation, only the number of charging cycles should be taken into account.

Assuming a lifespan of approx. 2,000 charging cycles [25], the built-in batteries can last almost the entire lifespan of the vehicle: e.g. 3 charging cycles per week for 13 years. The additional battery 
packs at the swapping stations are charged 1-2 times a day and would only be usable for approx. 3.7 years at 1.5 charging cycles per day $(2,000 /(1.5 * 365))$. This means that they must be replaced 3.5 times during the life of the built-in batteries (13 years / 3.7 years). Taking this into account in the above comparison,

$(30 \mathrm{kWh}+(3.5 * 45 \mathrm{kWh} * 5 \%)) / 75 \mathrm{kWh}=50.5 \%$

of the battery capacity are still required.

Of these,

$30 \mathrm{kWh} /(30 \mathrm{kWh}+(3.5 * 45 \mathrm{kWh} * 5 \%))=79.2 \%$

are used as built-in batteries in the vehicles and $20.8 \%$ as additional battery packs.

\subsection{Impact on the environmental balance of BEVs}

In the study mentioned at the beginning [01], the environmental balance of a typical medium-sized $\mathrm{BEV}$ is compared with similar vehicles equipped with petrol and diesel engines. Among other things, the greenhouse gas emissions of the vehicles are determined there, taking into account the progress expected by 2030 in battery development and the increase in renewable energies. The entire life cycle of the vehicles is examined, but slightly lower battery capacities are used as a basis.

If the results determined in [01] are transferred to vehicles with the battery capacities considered in section 3.3, the values shown in Fig. 5 are obtained.

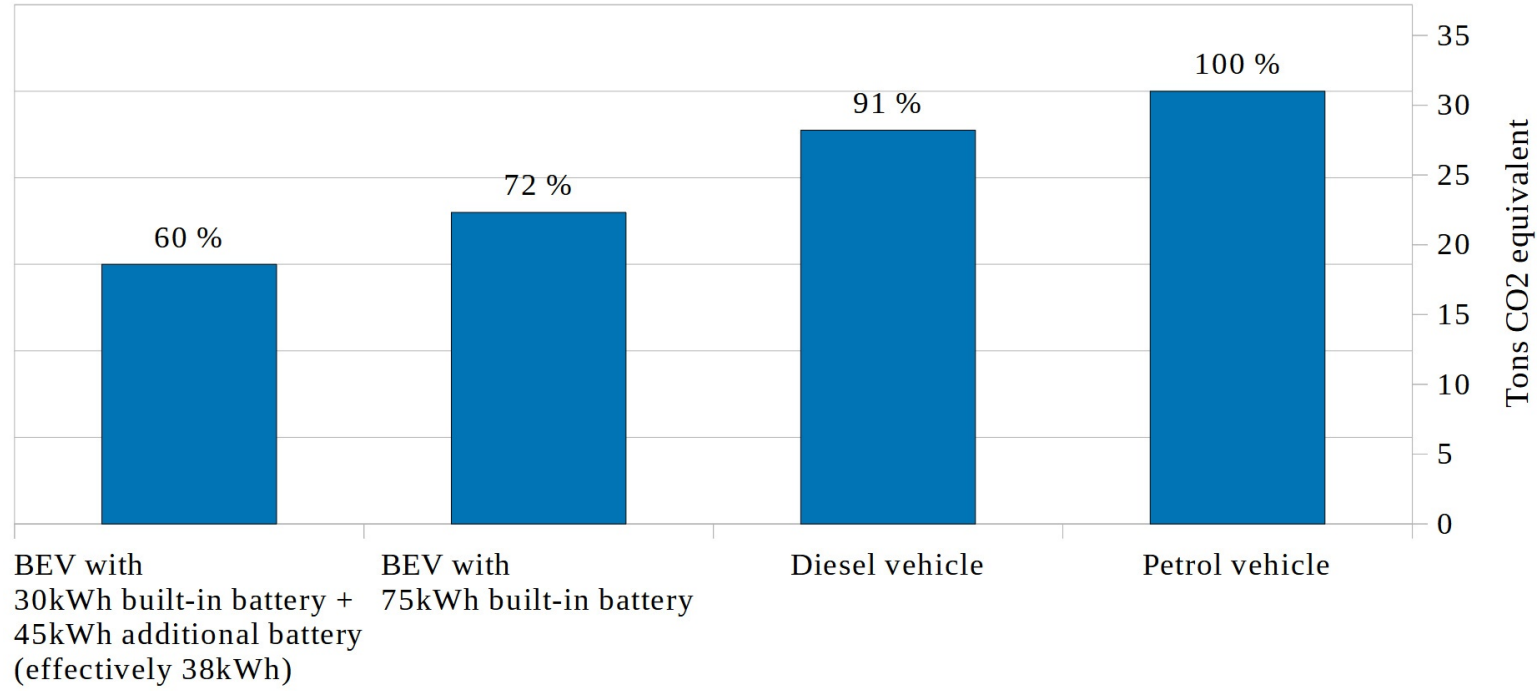

Fig. 5: Comparison of greenhouse gas emissions expected for various vehicles in 2030,

Numerical values according to [01], adjusted* to the different battery capacities of the BEVs considered here. The entire life cycle of the vehicles with a lifetime mileage of 150,000 km was taken into account. The European electricity mix expected for 2030 was assumed for battery production, and the German electricity mix for 2030 was assumed for traction energy.

*The share of emissions allocated to the battery capacity was interpolated/extrapolated linearly.

In the estimation carried out in the previous section (3.3) using the example of BEVs with a $75 \mathrm{kWh}$ battery, the proposed concept resulted in a reduction of the battery capacity to an average of approx. $38 \mathrm{kWh}$ per vehicle $(50.5 \% * 75 \mathrm{kWh})$. In a direct comparison of the two BEV variants, this means that the proposed concept will enable a greenhouse gas reduction of approx. $16 \%$ in the medium term. At present, the savings effect would be significantly greater, as battery technology and the electricity mix available for production are not yet as environmentally friendly as expected for 2030. 
This consideration does not take into account the greenhouse gas emissions caused by the battery transports (see section 4.3), but only a minor contribution to the overall balance is to be expected due to the comparatively low transport capacity required.

With regard to the consumption of battery-specific raw materials (lithium, cobalt, nickel, etc.), it can be stated that almost twice the number of vehicles can now be operated with the same quantity. The problem of environmentally friendly recycling of the decommissioned batteries is also reduced accordingly.

\section{Considerations about infrastructure and logistics for additional batteries}

\subsection{Preconditions and objectives}

- Since the swapping stations are only needed when long-distance journeys are made with the $\mathrm{BEV}$, they should be set up primarily along motorways.

- The quantity of battery packs held available at the swapping stations should be sufficient for the average demand of the vehicle fleet. Foreseeable traffic peaks (e.g. the beginning of holidays) should be secured by logistic measures.

\subsection{Rough estimation of the number of swapping stations required}

In most cases, the battery is changed in such a way that an additional battery pack is taken in at the beginning of the journey and released again at the end of the journey. In fewer cases, an empty battery pack is replaced by a full one or the above-mentioned procedures are carried out with 2 battery packs simultaneously. These operations will take different times. On average, it should be assumed here that it takes about 6 minutes to completely change a battery (installation and removal). For comparison: The company NIO states a time requirement of 3 minutes for a battery change with its technology [26].

Assuming that a (single-lane) swapping station can thus change approximately 10 battery packs per hour and the demand is spread over 10 hours per day, a station can change approximately 100 battery packs per day. If, as described above, $5 \%$ of the vehicles have to be supplied with a maximum of 2 additional batteries per day, there is a need for swapping stations amounting to $5 \% * 2 / 100=0.1 \%$

of the number of vehicles.

For general orientation, this result can be compared with that of a study on the charging infrastructure needs for long-distance travel by electric vehicles in Denmark [27]. In the "highdemand scenario for 2020", a need is determined there using other means, in which the number of BEVs and swapping stations are in a very similar ratio.

Each station should be able to hold 50 battery packs (100 battery changes when the batteries are used twice a day). Under the above assumptions, at least 5 hours are then available for charging the batteries, which makes lifetime preserving charging possible.

If 5 million BEVs of the target figures for Germany in 2030 were equipped with the technology presented, there would be a need for 250,000 battery packs in 5,000 swapping stations. If the 360 motorway petrol stations [28] and 190 car service stations near the motorways[29] were to be equipped with battery swapping stations as a matter of priority, approximately 9 single-lane stations would be required at each of these petrol stations.

\subsection{Logistics}

Logistical measures in the form of transportation of the battery packs may be necessary if the 
distribution of the battery packs to the swapping stations no longer meets demand. Appropriate measures will always be necessary to a lesser extent.

The transport effort is more than offset by the energy savings from the lower weight of the BEVs in normal operation without an additional battery pack: Assuming, for example, that an average of $20 \%$ of the exchange battery packs have to be transported over $300 \mathrm{~km}$ for this purpose, a weight of approx. $260 \mathrm{~kg}$ for a $45 \mathrm{kWh}$ battery pack (energy density $175 \mathrm{Wh} / \mathrm{kg}$ [30]) results in a transport capacity of

$250,000 * 20 \% * 0.26 \mathrm{t} * 300 \mathrm{~km}=3.9$ million tonne-kilometres

per day.

This contrasts with the reduced weight of 95\% of vehicles that are on the road without an additional battery pack. The weight of the exchange slot and additional DC/DC converter in the vehicle should be taken into account here at approximately $20 \mathrm{~kg}$. Since the average daily distance travelled by all private vehicles in Germany is about $39 \mathrm{~km} /$ day [21], for the 95\% "short distance drivers" 20 $\mathrm{km} /$ day may be assumed. Accordingly,

$5,000,000 * 95 \% *(0.26 \mathrm{t}-0.02 \mathrm{t}) * 20 \mathrm{~km}=22.8$ million tonne-kilometres

per day can be saved.

A reduction of additional battery transports can be achieved by a suitable reservation system. As the built-in batteries can be recharged while driving with an exchangeable battery pack, the vehicles are flexible within certain limits with regard to the exact pick-up, change and drop-off location for the additional battery. This can be used specifically to support logistics.

\subsection{Balancing of peak demand}

In order to avoid bottlenecks and search traffic, an online reservation system could also be useful, e.g. one that works automatically via the on-board computer and the navigation system (see section 5.3). If there are problems with the availability of battery packs, there is of course also the option of charging the built-in battery at a "conventional" charging station.

Traffic peaks during holiday periods are a greater challenge. However, all variants of BEVs are affected by this. The following concept could provide a remedy: During holiday periods, some of the BEV drivers are provided with a free additional battery pack for a limited time, which does not participate in the change regime. This battery pack contains its own charger and can thus be charged "conventionally" together with the built-in battery. After the agreed time, the battery must be returned to where it was borrowed (e.g. in the workshop). The battery packs come from a central reserve and are always distributed to areas where heavy holiday traffic is expected. With this concept, the logistics effort during holidays could be reduced and "conventional" charging infrastructure could be used to smooth the peak.

\section{Considerations for the loan of exchangeable additional batteries for electric vehicles}

\subsection{Preconditions and objectives:}

- Participation in the loan system is voluntary. Those who only use their vehicle for shorter distances, are satisfied with longer charging times or want to purchase a larger battery on their own, do not need this technology.

- The system described below is intended to ensure that no personal movement profile can be created through battery lending. 
- Security for the rental company (against theft, late return and manipulation when making the reservation) shall be achieved.

- A capital reserve for the (pro rata) financing of the available battery packs is to be built up. The actual rental fee should not be significantly higher than the fee at a public charging station.

- Since the battery packs available at the swapping stations can be used to stabilise the energy supply grid, this should be used for a portion of the financing.

\subsection{Battery lending scenario}

In order to participate in the loan system, one must register for it and make a deposit (see figure 6). In return one receives a deposit card (smart card, similar to a credit card). This is not personal, but contains a unique identification and can be used to generate a transaction number if required. The deposit can be refunded by returning the card (after a certain period of notice). The amount of the deposit (e.g. $500 €$ ) is a fraction of the amount saved when buying a vehicle due to the smaller battery size.

The card is retained by the swapping station when a battery pack is borrowed and another (different) card is issued when it is returned. When operating with an additional battery pack, a smart device integrated in the battery pack takes over the function of the card.

The rental fee for a battery pack corresponds to the energy content and is valid for max. 24 hours. If the battery is returned later, a full rental fee is due per 24 hours or part thereof.

Battery modules can only be charged at the swapping stations, as there is no charger for them on board the vehicle. This saves money, weight and prevents the additional batteries from not being returned. It is possible to permanently equip the exchange slot with its own battery pack, which then has an integrated charger and can be charged together with the built-in battery. In this case, participation in the loan system is not possible.

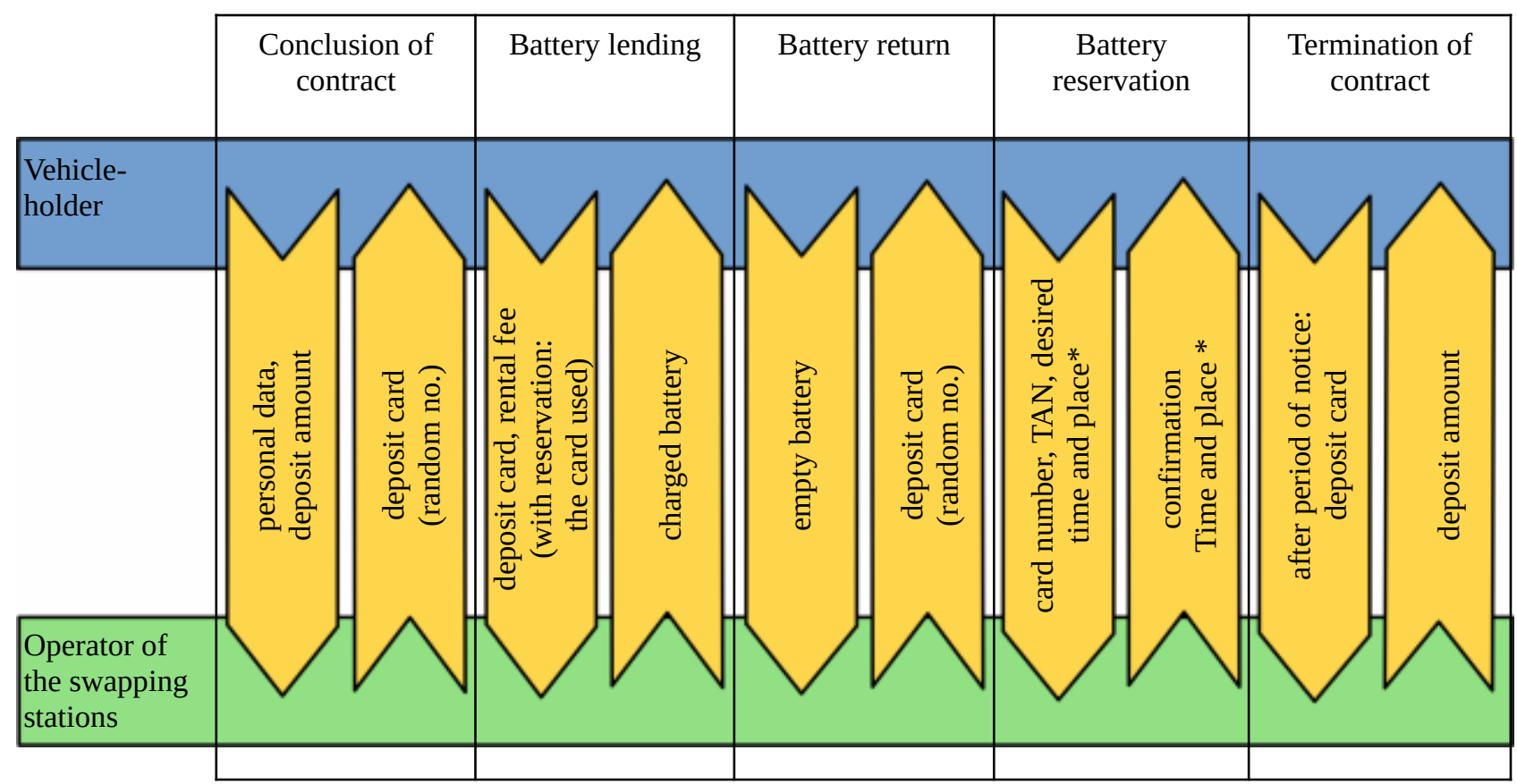

*) via anonymous data connection

Figure 6: Battery lending procedures 


\subsection{Reservation of a battery pack}

If required, a charged battery pack can be reserved in advance at a swapping station by specifying the card identification or the identification of the currently installed battery pack. To prevent manipulation, a transaction number is also used, which is generated with the deposit card or with the smart device of the currently installed battery pack. Reservations are only accepted if the identification and transaction numbers are valid.

The deposit card can be inserted into a specially designed slot in the vehicle. This protects it from loss and theft. In addition, the current identification and transaction number of the card (or the currently installed battery pack) can be displayed in order to make reservations.

In the future, reservations can also be made automatically by the on-board computer and an online reservation system when a longer route is planned. Such a reservation system is described in [31]. Communication for this should occur via a secure channel in the vehicle's Internet connection. Further improvement of security would be possible if communication on the Internet for this purpose could be carried out via the deposit card and smart device with an IP address independent of the vehicle. This would prevent any assignment to a vehicle or a person.

\subsection{Costs and fees}

In [32], an analysis of the optimised operation of exchange stations is carried out, based on corresponding pilot projects in China. This analysis takes into account the charging costs, depreciation costs, operating and maintenance costs, but not the basic investment. It can be shown that by an optimised mode of operation with commercial use of their grid-stabilising function, exchange stations can be operated economically and fees acceptable to the customers are possible.

This result can serve as a guide, but is not directly transferable to the concept proposed here. On the one hand, the costs for the transport of the battery packs (see section 4.3) must also be taken into account here, and on the other hand the proposed deposit fee provides a capital stock for the basic investment.

\section{Results and conclusions}

The concept presented here can save a considerable part of the battery capacity required for the entire vehicle fleet without causing disadvantages for the user. The lower battery capacity leads to an improvement in the environmental balance, in particular to a significant reduction in greenhouse gas emissions attributed to the vehicles, and there are cost advantages. The battery swapping technology also eliminates the problems with limited range, long recharging times or extremely high charging power when driving long-distance.

This concept is particularly effective in the short and medium term as long as a large proportion of the vehicles are still privately owned and therefore need to be particularly flexible in their use. For rental vehicles, which are expected to play a major role in the long term, a comparable effect can also be achieved by keeping vehicles with different sizes of built-in batteries in stock and then selecting them according to the planned driving route.

The characteristics of the concept presented are advantageous for its practical implementation. The acceptance by customers and manufacturers can thus be improved compared to previous battery swapping systems.

The infrastructure necessary such as battery swapping stations can be constructed with comparatively little effort, as it is only needed on average for $5 \%$ of the BEVs and will only be used for a short duration at a time. Suitable technology has already been available for some time and can be advantageously integrated into the energy supply grid. 
The loan system for the additional batteries can be designed to be convenient and affordable for the customers. It is possible for information security as well as data protection to be strictly complied.

These results are the product of rather rough estimates and simple considerations. All the issues raised here should be further analysed by more detailed investigations. However, they already show the potential this technology offers. So far, there are only a few academic studies and apparently no traffic policy concepts that deal with it. Considering the enormous tasks that have to be carried out in the transport sector to achieve the climate goals, it would certainly be justified to examine this idea in more detail.

In principle, the same transport policy measures would be needed to realise the scenario presented as for the introduction of the current electric vehicles: further increasing environmental requirements and funding the necessary infrastructure. Another important prerequisite would be the creation of a standard for the exchangeable battery packs. Obviously the work required to implement this will take some time. Therefore it would be all the more important to start as soon as possible.

Funding: This research did not receive any specific grant from funding agencies in the public, commercial, or not-for-profit sectors.

Conflicts of Interest: The author declares that he has no known competing financial interests or personal relationships that could have appeared to influence the work reported in this paper.

\section{References}

[01] Agora Verkehrswende (2019). Klimabilanz von Elektroautos. Einflussfaktoren und Verbesserungspotenzial, https://www.agora-verkehrswende.de/fileadmin/Projekte/2018/Klimabilanz von Elektroautos/ Agora-Verkehrswende 22 Klimabilanz-von-Elektroautos WEB.pdf

[02] Aral AG. Aral Studie: Trends beim Autokauf 2019, https://www.aral.de/content/dam/aral/business-sites/de/global/retail/presse/broschueren/aral-studietrends-beim-autokauf-2019.pdf

[03] The Federal Government. Climate action / Traffic and transport, https://www.bundesregierung.de/breg-en/issues/climate-action/verkehr-1674024; [accessed 25 June 2020].

[04] Fraunhofer ISI (2020). Batterien für Elektroautos: Faktencheck und Handlungsbedarf, https://www.isi.fraunhofer.de/content/dam/isi/dokumente/cct/2020/Faktencheck-Batterien-fuer-EAutos.pdf

[05] Jungmeier G, Canella L, Pucker-Singer J, Beermann M. Geschätzte Treibhausgasemissionen und Primärenergieverbrauch in der Lebenszyklusanalyse von Pkw-basierten Verkehrssystemen, 12 September 2019, https://res.cloudinary.com/adacde/image/upload/v1572625374/ADAC-eV/KOR/ Text/PDF/LCA Tool - Joanneum Research zp22wt.pdf

[06] Khalid M R, Alam M S, Sarwar A, Asghar J. A Comprehensive review on electric vehicles charging infrastructures and their impacts on power-quality of the utility grid. eTransportation 2019;1:100006, https://doi.org/10.1016/j.etran.2019.100006.

[07] Tomaszewska A, Chu Z, Feng X, et al. Lithium-ion battery fast charging: A review.

eTransportation 2019;1:100011, https://doi.org/10.1016/j.etran.2019.100011. 
[08] Vera N. Tesla drivers stuck waiting 4 hrs+ at Central Coast charging stations during holiday travel, Keyt News, 27 December 2019, https://keyt.com/lifestyle/2019/12/27/tesla-drivers-stuckwaiting-4-hrs-at-central-coast-charging-stations-during-holiday-travel/

[09] Ankündigungstext zu DIN IEC/TS 62840-1 VDE V 0122-40-1:2017-06.

Batteriewechselsysteme für Elektrofahrzeuge, https://www.vde-verlag.de/normen/0100384/din-iects-62840-1-vde-v-0122-40-1-2017-06.html [accessed 25 October 2020].

[10] Wikipedia. Better Place (Company), https://en.wikipedia.org/wiki/Better Place (company); [accessed 25 June 2020].

[11] Gaffoglio E O, Clarke A, Brown M L (Tesla Inc.). Battery Swapping System And Techniques, United States Patent Application 20170259675, 14 September 2017 http://appft.uspto.gov/netacgi/nph-Parser?Sect1=PTO1\&Sect2=HITOFF\&d=PG01\&p=1\&u= \%2Fnetahtml\%2FPTO\%2Fsrchnum.html\&r=1\&f=G\&l=50\&s1= \%2220170259675\%22.PGNR.\&OS=DN/20170259675\&RS=DN/20170259675

[12] Hanley S. NIO Completes More Than 500,000 Battery Swaps, CleanTechnica, 31 May 2020, https://cleantechnica.com/2020/05/31/nio-completes-more-than-500000-battery-swaps/

[13] Shelley G. Electric Car Range And Affordability: Is There A Magic Combo? Inside EVs, 05 November 2019, https://insideevs.com/news/380555/ev-range-ev-market-evolution-exposed/

[14] GoingElectric Elektroauto Forum. Szenario zur Verbesserung des Preis-LeistungsVerhältnisses und der Umweltbilanz batterieelektrischer Autos, 14.01.2020, https://www.goingelectric.de/forum/viewtopic.php?f=12\&t=54116; [accessed 25 June 2020].

[15] Holder D, Maier T. New Battery Concepts. MTZ Worldw 73, 26-30 (2012). https://doi.org/10.1007/s38313-012-0223-5.

[16] Barreras JV, Pinto C, de Castro R, Schaltz E, Andreasen SJ, Rasmussen PO et al. A novel BEV concept based on fixed and swappable li-ion battery packs. In Proceedings of the 2015 Tenth International Conference on Ecological Vehicles and Renewable Energies (EVER). Monte-Carlo: IEEE Press. 2015. p. 1-8, https://doi.org/10.1109/EVER.2015.7112983

[17] Barreras JV, Pinto C, de Castro R, Schaltz E, Juhl Andreasen S, Rasmussen PO et al.

Evaluation of a Novel BEV Concept Based on Fixed and Swappable Li-Ion Battery Packs. I E E E Transactions on Industry Applications. 2016 Nov;52(6):5073 - 5085, https://doi.org/10.1109/TIA.2016.2585554

[18] Adegbohun F, von Jouanne A, Lee KY. Autonomous Battery Swapping System and Methodologies of Electric Vehicles, Energies 2019, 12(4), 667. https://doi.org/10.3390/en12040667

[19] Sun P, Bisschop R, Niu H, Huang X. A Review of Battery Fires in Electric Vehicles. Fire Technology 2020, 56, 1361-1410. https://doi.org/10.1007/s10694-019-00944-3

[20] Wang Y, Wang L, Li M, Chen Z. A review of key issues for control and management in battery and ultra-capacitor hybrid energy storage systems. eTransportation 2020;4:100064, https://doi.org/10.1016/j.etran.2020.100064.

[21] Forschungs-Informations-System. Pkw-Jahresfahrleistungen und -Wegelängen, 19 November 2019, https://www.forschungsinformationssystem.de/servlet/is/80865/

[22] Office for Official Publications of the European Communities. Document number 32009M5518, 24.07.2009, https://ec.europa.eu/competition/mergers/cases/decisions/m5518 2009072420310 en.pdf

[23] EFAHRER.com. Elektroautos 2020 in der Übersicht, https://efahrer.chip.de/elektroautos [accessed 25 October 2020]. 
[24] Han X, Lu L, Zheng Y, Feng X, Li Z, Li J, Ouyang M. A review on the key issues of the lithium ion battery degradation among the whole life cycle. ETransportation 2019;1:100005, https://doi.org/10.1016/j.etran.2019.100005.

[25] Battery University. BU-1003a: Battery Aging in an Electric Vehicle (EV) https://batteryuniversity.com/learn/article/bu 1003a battery aging in an electric vehicle ev; [accessed 25 June 2020].

[26] NIO Inc. NIO Power: An Experience Beyond Refueling, https://www.nio.com/nio-power [accessed 25 October 2020].

[27] Christensen L, Kaplan S, Jensen TC, Røpke S, Olsen A. (2018) The Recharging Infrastructure Needs for Long Distance Travel by Electric Vehicles: A Comparison of Battery-Switching and Quick-Charging Stations. In: Thill JC. (eds) Spatial Analysis and Location Modeling in Urban and Regional Systems. Advances in Geographic Information Science. Springer, Berlin, Heidelberg. https://doi.org/10.1007/978-3-642-37896-6 15

[28] Ahlswede A. Anzahl der Tankstellen in Deutschland bis 2020, statista, 27 April 2020, https://de.statista.com/statistik/daten/studie/2621/umfrage/anzahl-der-tankstellen-in-deutschlandzeitreihe/

[29] Bundesministerium für Verkehr und digitale Infrastruktur. Nebenbetriebe / Rastanlagen, https://www.bmvi.de/SharedDocs/DE/Artikel/StB/nebenbetriebe-rastanlagen.html; [accessed 25 June 2020].

[30] EUCAR. Battery requirements for future automotive applications, July 2019, https://eucar.be/wp-content/uploads/2019/08/20190710-EG-BEV-FCEV-Battery-requirementsFINAL.pdf

[31] Adler J D, Mirchandani P B. Online routing and battery reservations for electric vehicles with swappable batteries, Transportation Research Part B: Methodological 2014; Volume 70, Pages 285302, ISSN 0191-2615, https://doi.org/10.1016/j.trb.2014.09.005.

[32] Liang Y, Zhang X, Xie J, Liu W. An Optimal Operation Model and Ordered Charging/Discharging Strategy for Battery Swapping Stations. Sustainability. 2017; 9(5):700, https://doi.org/10.3390/su9050700 